\title{
вмJ Global Health Achieving scale, sustainability and impact: a donor perspective on a mobile health messaging service and help desk (MomConnect) for South African mothers
}

Joanne Peter

To cite: Peter J. Achieving scale, sustainability and impact: a donor perspective on a mobile health messaging service and help desk (MomConnect) for South African mothers. BMJ Glob Health 2018;3:e000562. doi:10.1136/ bmjgh-2017-000562

Handling editor Seye Abimbola

Received 11 September 2017 Revised 4 December 2017 Accepted 9 December 2017
Check for updates

Global Community Impact, Johnson \& Johnson, Cape Town, South Africa

Correspondence to Dr Joanne Peter; jpeter4@its.jnj.com

\section{INTRODUCTION}

Some of the first evidence of the impact of mobile health was through behaviour change communication, where simple text messaging was shown to improve healthy behaviours like smoking cessation and blood glucose monitoring. ${ }^{12}$ Early studies were concentrated in high-income settings, but given the ubiquity of mobile telephony in low-income countries and the burden of ill health, it did not take long for attention to shift to emerging markets like Africa and Asia.

Maternal and child health was an area of priority. Low/middle-income countries were focused on meeting the maternal and child survival targets of Millennium Development Goals 4 and 5, and many of the evidence-based life-saving interventions in the pregnancy and postpartum period rely on changes in individual and household practices: improved antenatal nutrition, handwashing, exclusive breastfeeding, early recognition of childhood illness. Pregnant women and new mothers are an unusually motivated patient group, with a thirst for information and many shared questions and concerns. Mobile phones represented a powerful mechanism for delivering health information directly into the hands of women and families.

In 2010-after early involvement in the Text4baby programme in the USA-Johnson \& Johnson made a commitment under Every Woman, Every Child to fund mobile messaging programmes to reach low-income pregnant women and new mothers with vital health information in six countries: India, Bangladesh, South Africa, China, Nigeria and Mexico. ${ }^{3}$

These mobile messaging programmes were designed with a specific emphasis on behaviour change communication, with a theory of change that hypothesised that

\section{Summary box}

Mobile-based behaviour change communication has been pursued to reduce maternal and child morbidity and mortality in low-resource settings.

- Several messaging programmes have achieved high user numbers but have struggled to match this with financial and institutional sustainability and evidence of improved health outcomes (scale, sustainability and impact).

- MomConnect is a flagship South African National Department of Health service that uses mobile technology to register pregnant women, send them vital health information to support pregnancy and the first year of life and provide channels for patient queries and feedback.

- Over 1.7 million women have been registered to the platform since its launch in August 2014, with over $60 \%$ coverage of all pregnant women nationally.

- MomConnect has combined significant upfront risk capital from donors and strong government leadership to create a universally accessible platform integrated into the South African health system.

- The initially simple concept of a behaviour change communication programme has become much more: MomConnect generates demand for health services while also collecting data to strengthen supply and presents an opportunity to link mothers and children to further health and social services.

increased access to information would result in adoption of healthy behaviours and increased demand for health services. ${ }^{4}$ Philanthropic funding was combined with an in-kind contribution of mobile content developed by BabyCenter-a well-known Johnson \& Johnson-owned pregnancy and parenting website with 11 international sites. This evidence-based and expert-reviewed content was designed per the motivation, ability, trigger behaviour model of $\mathrm{Fogg}^{5}$ and employed principles to establish an emotional connection 
with the mother to motivate user engagement and subsequent behaviour change. These included carefully targeting the messaging by pregnancy stage or baby's age, adopting a warm and relatable tone and including parenting support and content to promote bonding, alongside more technical health promotion messages.

\section{SCALE, SUSTAINABILITY AND IMPACT—AN UNEASY TRIAD}

Johnson \& Johnson's commitment aimed to demonstrate that programmes could be launched to reach scale, sustainability and impact. This is not an easy triad to achieve, because the three dimensions are often at odds-for example, scale may threaten financial sustainability by driving up programme costs. In lower-income populations, mobile phones are commonplace, but most are used for the simple functions of voice calling and text messaging. Programmes attempting to deploy these universally accessible technologies to large numbers of users quickly earn a hefty price tag due to the fixed per-unit pricing of these modalities, with no economies of scale. Though usage of more cost-effective mobile web and data services is increasing at a rapid rate, ${ }^{6}$ programmes need to be cautious about shifting completely to technologies that exclude those women and families at the low end of the socioeconomic spectrum who need information services the most.

This frequently creates a funding gap when early catalytic grant funding has been spent, but programmes have been unable to secure the resources required to support implementation at national scale. Larger-typically risk averse-donors and payers (such as bilaterals and national governments) seldom engage without clear evidence of programme effectiveness, but despite high reported rates of user satisfaction and empowerment, ${ }^{7}$ clear evidence on behaviour change to improve maternal and infant survival (though emerging ${ }^{8}$ ) has been slow to obtain. ${ }^{10}{ }^{11}$ It is also very difficult to build a commercial business case around behaviour change communication to a low-income audience, because direct user fees discourage adoption of preventive health products and services. $^{12}$

Seven years after the initial Johnson \& Johnson commitment, three of the six country programmes (Bangladesh, India and South Africa) have reached more than a million mothers each, illustrating that it is possible for messaging programmes to be implemented at significant scale. Sustainability and impact will take longer to demonstrate reliably.

\section{THE CASE OF MOMCONNECT}

MomConnect, South Africa's maternal mobile messaging service, may be the first programme on a course to achieving all three dimensions-scale, sustainability and eventual health impact - though not always in the ways that were originally envisaged. The South African National Department of Health runs and endorses the service as an official instrument of the state health system; hence, the programme is no longer aiming simply for large numbers, but rather for true universal coverage. It has achieved over $60 \%$ coverage of the pregnant population through $95 \%$ of South African public health clinics.

This has required some critical adjustments to the programme from its origins in several non-profit-led initiatives. $^{13}$ For example, MAMA South Africa-a precursor programme to MomConnect funded by Johnson \& Johnson between 2011 and 2013-reached over 600000 users, but did so through a mobile website that was completely inaccessible to $25 \%$ of the South African population using the most basic mobile phones. This approach prevented formal integration into the national health system because this would have denied service to an important segment of the population.

MomConnect, by contrast, is accessible through all mobile phones. To achieve this, the programme had to make choices that were counter-intuitive for long-term financial sustainability, particularly in the use of short message service (SMS) and reverse-billed unstructured supplementary service data (USSD) for user registration and messaging.

In addition, the service is no longer just one way, but instead includes mechanisms for two-way interaction between the pregnant mother and the health system through USSD-based surveys and a help desk. This enables real-time data collection on user knowledge, attitudes, practices and experiences of service delivery to inform healthcare improvements. ${ }^{14}$ Early research has demonstrated the feasibility of further help desk automation through machine learning and artificial intelligence. ${ }^{15}$

MomConnect messaging engages and empowers users and fosters a relationship of trust with the service and the health system itself. In a sample of nearly 10000 women telephonically surveyed, with a response rate of over one in five ( $n=1999), 98 \%$ found the messages helpful, $77 \%$ felt better prepared for delivery, $81 \%$ shared their messages with family and friends and $70 \%$ wanted more messages per week. ${ }^{16}$

Most importantly, by engaging holistically with both demand and supply sides of the health system, the value proposition of MomConnect has changed. The most significant impact of MomConnect may not be achieved via the direct effect of the messaging itself, but rather by creating a national platform that directly connects to over a million mothers and that has been designed to permit easy integration with other information systems. ${ }^{17}$ In the future, as MomConnect links with other systems such as electronic medical records, the National Health Laboratory Service, the population database and Department of Social Development databases, a mother's enrolment in MomConnect could become her first step towards accessing a continuum of support that extends from her first antenatal appointment right through to social grants and early learning subsidies for her child.

This has only been possible through a substantial donor investment in MomConnect and a government commitment to going to national scale right from the start. MomConnect has established a simple platform that can be adapted over time to add features and functionality 
of increasing complexity. The service is far from perfect, but as the mobile market evolves and smartphone penetration increases, more sophisticated and less expensive technology options can be added to incrementally shift eligible users away from USSD and SMS, while reserving these modalities for the most vulnerable users.

\section{THE ROLE OF PUBLIC-PRIVATE PARTNERSHIP}

Government stewardship and integration into the health system have both been identified as enablers that allow mobile health programmes to scale. ${ }^{18}$ Many donorfunded programmes aim for eventual government adoption, but few get there. MomConnect is an unusual example of a true public-private partnership. Private funders, with a larger appetite for risk, have contributed upfront investment and technical know-how, but only in the context of public leadership and an enabling policy environment. As the programme demonstrates its value, public funding has been committed to take over the core elements of registration, messaging and the help desk. However, as a technology platform MomConnect needs to continue to be agile and to evolve in line with the technology landscape and the habits and needs of its users. It will therefore always require some degree of private risk capital to fund innovation at the margins of the service.

\section{CONCLUSION}

MomConnect launched alongside several other mobile messaging programmes for mothers, all seeking to prove their effectiveness and establish models for long-term sustainability and success. Through an unusual combination of sustained donor funding and marked government commitment, it established deep roots into the public health system and a path towards universal service coverage. The initially simple concept of a behaviour change communication programme has become much more: now that the service is at national scale, MomConnect serves as an important tool for data collection on pregnant mothers, where they receive care, and their experience of service quality. The platform will need to take advantage of newer technologies to reduce costs, while continuing to build on the initial service offering to increase its value for mothers, health workers and the health system at large.

Acknowledgements The support provided by John Snow, Inc. (JSI) in the President's Emergency Plan for AIDS Relief (PEPFAR) and United States Agency for International Development (USAID)-funded MEASURE Evaluation Strategic Information for South Africa (MEval-SIFSA) project to enable this publication is acknowledged with gratitude.

Contributors JP conceptualised and wrote the commentary.

Competing interests We have read and understood BMJ policy on declaration of interests. JP is employed by Johnson \& Johnson, one of the primary funders of MomConnect.

Provenance and peer review Not commissioned; externally peer reviewed.

Data sharing statement № additional data are available.

Open Access This is an Open Access article distributed in accordance with the Creative Commons Attribution Non Commercial (CC BY-NC 4.0) license, which permits others to distribute, remix, adapt, build upon this work non-commercially, and license their derivative works on different terms, provided the original work is properly cited and the use is non-commercial. See: http://creativecommons.org/ licenses/by-nc/4.0/

(C) Article author(s) (or their employer(s) unless otherwise stated in the text of the article) 2018. All rights reserved. No commercial use is permitted unless otherwise expressly granted.

\section{REFERENCES}

1. Cole-Lewis H, Kershaw T. Text messaging as a tool for behavior change in disease prevention and management. Epidemiol Rev 2010;32:56-69.

2. Krishna S, Boren SA, Balas EA. Healthcare via cell phones: a systematic review. Telemed J E Health 2009;15:231-40.

3. Johnson \& Johnson. Fulfilling our MDG Commitment. https://www. jnj.com/our-giving/our-commitment-to-improving-the-health-ofwomen-and-children (accessed 28 Aug 2017).

4. Mobile Alliance for Maternal Action. Research agenda. 2015 http://www.mhealthknowledge.org/sites/default/files/MAMA\% 20Research\%20Agenda_FINAL_March\%202015_1.pdf (accessed 28 Aug 2017).

5. Fogg BJ. The future of persuasion is mobile. In: Fogg BJ, Eckles D, eds. Mobile persuasion: 20 perspectives on the future of behavior change. Stanford, CA: Stanford Captology Media, 2007:5-11.

6. Pew Research Center. Smartphone ownership and internet usage continues to climb in emerging economies. $2016 \mathrm{http}: / / \mathrm{www}$. pewglobal.org/2016/02/22/smartphone-ownership-and-internetusage-continues-to-climb-in-emerging-economies/ (accessed 28 Aug 2017)

7. Martinez K, Uekusa S. National survey of text4baby participants. California State University San Marcos (CSUSM). 2013 http://www. csusm.edu/anthropology/docsandfiles/Text4baby.pdf (accessed 28 Aug 2017).

8. Lund S, Hemed M, Nielsen BB, et al. Mobile phones as a health communication tool to improve skilled attendance at delivery in Zanzibar: a cluster-randomised controlled trial. BJOG 2012;119:1256-64

9. Coleman J, Bohlin KC, Thorson A, et al. Effectiveness of an SMSbased maternal mHealth intervention to improve clinical outcomes of HIV-positive pregnant women. AIDS Care 2017;29:890-7.

10. Gurman TA, Rubin SE, Roess AA. Effectiveness of mHealth behavior change communication interventions in developing countries: a systematic review of the literature. J Health Commun 2012;17(Suppl 1):82-104.

11. Higgs ES, Goldberg AB, Labrique AB, et al. Understanding the role of $\mathrm{mHealth}$ and other media interventions for behavior change to enhance child survival and development in low- and middle-income countries: an evidence review. J Health Commun 2014;19(Suppl 1):164-89.

12. J-PAL. Pricing preventive health products. https://www. povertyactionlab.org/policy-lessons/health/pricing-preventivehealth-products (accessed 28 Aug 2017).

13. Barron P, Peter J, LeFevre AE, et al. Mobile health messaging service and helpdesk for South African mothers (MomConnect) history, successes and challenges. BMJ Glob Health 2018;3(Suppl 2):e000559.

14. Barron P, Pillay Y, Fernandes A, et al. The MomConnect mHealth initiative in South Africa: Early impact on the supply side of $\mathrm{MCH}$ services. J Public Health Policy 2016;37(Suppl 2):201-12.

15. Engelhard M, Copley C, Watson J, et al. Optimising mHealth helpdesk responsiveness in South Africa: towards automated message triage. BMJ Glob Health 2018;3(Suppl 2):e000567.

16. Peter JE, Barron P, Pillay Y. Using mobile technology to improve maternal, child and youth health and treatment of HIV patients. S Afr Med J 2015;106:3-4

17. Seebregts C, Dane P, Parsons AN, et al. Designing for scale: optimising the health information system architecture for mobile maternal health messaging in South Africa (MomConnect). BMJ Glob Health 2018;3(Suppl 2):e000563.

18. Leon N, Schneider H, Daviaud E. Applying a framework for assessing the health system challenges to scaling up mHealth in South Africa. BMC Med Inform Decis Mak 2012;12:123.

19. Aranda-Jan CB, Mohutsiwa-Dibe N, Loukanova S. Systematic review on what works, what does not work and why of implementation of mobile health (mHealth) projects in Africa. BMC Public Health 2014;14:188. 